\title{
Biology-based Approach for Selective Extraction of Rare Earth Elements from Coal Byproducts
}

DAN PARK ${ }^{* 1}$, ZIYE DONG ${ }^{1}$, GAUTHIER DEBLONDE ${ }^{1}$, MAJID DOOLABI ${ }^{2}$, HONGYUE JIN ${ }^{2}$, HEILEEN HSU-KIM ${ }^{3}$, JOSEPH COTRUVO $^{4}$, AND YONGQIN JIAO ${ }^{1}$

${ }^{1}$ Lawrence Livermore National Laboratory, Livermore, CA (*correspondence: Park36@1lnl.gov)

${ }^{2}$ University of Arizona, Tuscon, Az

${ }^{3}$ Duke University, Durham, North Carolina, USA

${ }^{4}$ Penn State University, University Park, PA

Rare earth elements (REEs) are indispensable components of many green energy technologies. However, refining REEs from raw materials using current technologies is energy intensive and environmentally damaging. Herein, we present the development of microbe and protein-based approaches for REE recovery from coal byproducts, an abundant and untapped potential source of REEs. Biosorption studies using engineered and native bacteria and leachates of lignite coal and Powder River Basin fly ash revealed that the REE recovery efficiency and product purity were dictated by the leachate solution matrix, with $\mathrm{Ca} / \mathrm{Mg}$ concentrations as the key drivers. Separation factors greater than 30 for $\mathrm{Nd}$ relative to nearly all non-REE metals were observed for both strains and leachates, highlighting the cell surface selectivity for REEs. To scale the biosorption operation, A. nicotianae was encapsulated within a permeable Si-sol gel matrix in high density for application in a packed bed bioreactor. The microbe particle columns were stable for reuse, retaining $>90 \%$ of the REE adsorption capacity after 10 consecutive adsorption/desorption cycles. Breakthrough column tests demonstrated the feasibility of a two-stage bioreactor design for sequential $\mathrm{Sc}$ and lanthanide/Y extraction from coal leachates. $\mathrm{A}>30$-bed volume increase in breakthrough point was observed for $\mathrm{Sc}$ compared to REEs/non-REE at $\mathrm{pH}$ 3.4, while selective lanthanide separation from non-REEs required a higher $\mathrm{pH}$ (5). Technoeconomic and life-cycle analyses support the economic potential and sustainability of this two-stage biosorption approach. Lastly, we explored the REE extraction efficacy of lanmodulin, a recently discovered protein from Methylobacterium extorquens that binds REEs with high affinity and selectivity. Future efforts will focus on immobilizing lanmodulin to enable a scalable process for REE recovery from low-grade feedstocks. 